Revta brasil. Bot., São Paulo, V.23, n.4, p.427-442, dez. 2000

\title{
Palinotaxonomia de espécies brasileiras de Salacia L. (Hippocrateaceae) ${ }^{1}$
}

\author{
VANIA GONÇALVES-ESTEVES ${ }^{2,4}$ e THEREZINHA SANT'ANNA MELHEM ${ }^{3}$
}

(recebido em 8 de dezembro de 1999; aceito em 16 de agosto de 2000)

\begin{abstract}
Palynotaxonomy of the Brazilian species of Salacia L. Hippocrateaceae). The palynotaxonomic study of the Salacia L. aimed to contribute to a better characterization as well as the circumscription and delimitation of this genus. The pollen grains of 21 species of the Salacia were studied. The pollen material was acetolyzed, measured, described and illustrated with photo or eletronmicrography (SEM). The analysis in SEM was used in order to elucidate the exine sculpture. The data obtained was statiscally analysed according to sample sizes. The pollen grains of Salacia are generally of medium size, oblate-spheroidal, reticulate to microreticulate, 3-colporate predominantly with a characteristic prominent apertural area. Salacia is a stenopalynous genus. However it was possible to make pollinic key with the results here obtained in light microscopy, and to segregate Salacia species or group of species using pollen characters. The present work has corroborated, by means of the pollen grains, the circumscription and generic delimitation concerning the Hippocrateaceae of South America.
\end{abstract}

RESUMO - (Palinotaxonomia de espécies brasileiras de Salacia L. (Hippocrateaceae). O estudo palinotaxonômico de Salacia L. teve como objetivo contribuir para a melhor caracterização, circunscrição e delimitação deste gênero. Os grãos de pólen de 21 espécies de Salacia foram acetolisados, medidos, descritos e ilustrados sob microscopia de luz e microscopia eletrônica de varredura (MEV). A análise sob MEV foi utilizada visando a elucidação de dúvidas sobre a ornamentação da exina. Constatou-se que os grãos de pólen são predominantemente de tamanho médio, reticulados a microrreticulados, 3-colporados, geralmente com uma característica área apertural proeminente. Salacia é um gênero estenopolínico. Entretanto, o pólen permitiu a confecção da chave polínica e a separação de diferentes espécies ou grupo de espécies de Salacia com base nos resultados obtidos sob microscopia de luz. O presente trabalho confirmou, por meio dos grãos de pólen, a circunscrição e a delimitação genérica da Hippocrateaceae da América do Sul.

Key words - Palynotaxonomy, Salacia, Hippocrateaceae, pollen

\section{Introdução}

A família Hippocrateaceae Juss. foi considerada por Bentham \& Hooker (1862) como uma tribo das Celastraceae constituída por apenas dois gêneros (Hippocratea L. e Salacia L.). Estes gêneros têm sido tradicionalmente aceitos para os representantes brasileiros das Hippocrateaceae, talvez pelo fato de tal posicionamento ter sido ratificado por Peyritsch (1878) na Flora Brasiliensis, embora Miers (1872) já houvesse dividido os representantes sul-americanos da família em 17 gêneros, conferindo-lhe uma caracterização mais precisa, que a distinguia das Celastraceae.

Smith (1940) fez uma revisão taxonômica das Hippocrateaceae da América do Sul, incluindo espécies brasileiras e, usando a inflorescência e os frutos

1. Parte da tese de doutorado da primeira autora, Departamento de Botânica, IB-USP.

2. Museu Nacional, Departamento de Botânica, Universidade Federal do Rio de Janeiro, Quinta da Boa Vista, São Cristóvão, 20940-040 Rio de Janeiro, RJ, Brasil.

3. Instituto de Botânica, Caixa Postal 4005, 01061-970 São Paulo, SP, Brasil.

4. Autor para correspondência como caracteres distintivos, reconheceu 12 gêneros para a família, dentre eles Hippocratea L. e Salacia L.

Segundo Smith (1940), Salacia possui 29 espécies sul-americanas distribuídas em nove grupos: grupo Arboreae [S. amplectens A.C. Sm., S. arborea (Leandro Sacr.) Peyr., S. cuspidata A.C. Sm., S. miqueliana Loes. e S. mosenii A.C. Sm.]; grupo Opacifoliae [S. insignis A.C. Sm. e S. opacifolia (Macbr.) A.C. Sm.]; grupo Acreanae [S. acreana A.C. Sm., S. megistophylla Standl. e S. spectabilis A.C. Sm.]; grupo Mucronatae, sem representantes brasileiros; grupo Multiflorae [S. multiflora (Lam.)DC.]; grupo Ellipticae [S. amygdalina Peyr., $S$. elliptica (Mart.) G. Don., S. gigantea Loes., $S$. impressifolia (Miers) A.C. Sm., S. juruana Loes., $S$. kanukuensis A.C. Sm., S. pachyphylla (Miers)Peyr. e S. solimoensis A.C. Sm.]; grupo Wrightiae, sem representantes brasileiros; grupo Caloneurae [S. calloneura A.C. Sm.]; grupo Crassifoliae [S. crassifolia (Mart.) G. Don e S. glomerata (Mart.) G. Don].

Posteriormente, Mennega (1984) descreveu Salacia bullata não conseguindo enquadrá-la em nenhum grupo aceito por Smith (1940) e, por isso, julgou pertinente formar um novo grupo ao qual associou S. amplectens, denominando-o Amplecten- 
tes. Segundo a autora este grupo fica posicionado entre os grupos Arboreae e Opacifoliae. Rizzini (1976) descreveu $S$. induta não enquadrando esta espécie em nenhum grupo de Smith (1940), comentando apenas sua afinidade com S. amygdalina.

Neste trabalho, em continuidade ao estudo palinológico das espécies de Hippocrateaceae ocorrentes no Brasil (Gonçalves-Esteves 1994, Gonçalves-Esteves \& Melhem 1998) foram estudados os grãos de pólen de 21 espécies de Salacia encontradas em vários ecossistemas e regiões do país.

\section{Material e métodos}

O material analisado foi retirado de exsicatas depositadas nos seguintes herbários: HBR, HRB, HUA, IAN, MG, MBM, NY, R, RB, SPF e US (siglas de acordo com Holmgren et al. 1990).

Para cada espécie determinou-se um espécimen como "padrão", que é citado abaixo, seguido de asterisco. Procurou-se estudar outros espécimens de cada espécie, denominados "materiais de comparação". Segue a relação do material estudado, coletado em diferentes regiões do Brasil; excepcionalmente utilizou-se material coletado fora do Brasil, quando este era o único disponível:

Salacia amplectens - BRASIL: PARÁ: rio Curuquetê, cachoeira Santo Antonio, G.T. Prance et al. 14191 (US)*. SURINAME: B. Maguire 24717 (IAN). S. amygdalina - BRASIL: RIO DE JANEIRO: Alto Macaé de Nova Friburgo, Glaziou 18156 (R)*; Serra dos Órgãos, rio Beira Flor, Markgraf 10195 (RB). S. arborea - Riedel 1086 (US). BRASIL: GoIÁs: BR 524, 1554'S e 5056'W, A. Araújo-Dias 76 (RB). S. bullata - BRASIL: AMAPÁ: Estrada até Matapi, atrás de Porto Grande, D.F. Austin et al. 7073 (NY); AMAZONAS: rio Jari, monte Dourado, 30/9/1968, N.T. Silva s.n. (IAN 127412); PARÁ: Santarém, reserva da SUDAM, C.S. Rosário et al. 1143 (IAN). S. caloneura - BRASIL: AMAZONAS: Itapiranga, rio Uatumã, 27/8/1979, C.A. Cid et al. s.n. (NY 852); PARÁ: Belém, J.M. Pires 3149 (IAN)*. S. crassifolia - BRASIL: BAHIA: Rio de Contas, a $1 \mathrm{~km}$ da cidade, estrada para Marcelino Moura, 9/9/1981, J.R. Pirani et al. s.n. (SPF 19016); GoIÁs: Cristalina, BR 040, G. Hatschbach 43089 (MBM)*; MATO Grosso: Cuiabá, 15-120 km além de Alto Araguaia, 25/8/1963, B. Maguire et al. s.n. (NY 56287). S. duckei - BRASIL: AMAzONAS: Esperança, rio Solimões, boca do Javari, A. Ducke 1575 (R)*. S. elliptica - BRASIL: DistRITO FEDERAL: 30 km de Brasília, 17/7/1966, H.S. Irwin et al. s.n. (NY 18245); Goiás: Flores de Goiás, L.C. Oliveira Filho 11 (HRB); MARANHÃO: Fontana, Palmeirinhas, 26/2/1983, E.L. Taylor et al. s.n. (NY 1015); RIO DE JANEIRO: Alto Macaé de Nova Friburgo, Glaziou 13582 (R); SANTA CATARINA: Itajaí, morro da Fazenda, R. Reitz \& R.M. Klein 1842 (HBR); idem, morro da Fazenda, R. Reitz \& R.M. Klein 1865 (HBR). S. gigantea - BRASIL: AMAZONAS: Camatian, R.L. Fróes 23976 (IAN). S. impressifolia - BRASIL: AMAZONAS: Manaus, margem do rio Negro, 7/4/1971, G.T. Prance et al. s.n. (NY 11743); Maués, J.M. Pires et al. 1184 (IAN); Tapurucuara, 26/9-14/10/1947, R.E. Schultes \& F. López s.n. (IAN 52593);
PARÁ: Alto Tapajós, Vila Nova, J.M. Pires 3993 (IAN); igarapé Assú, afluente do rio Arapicus, J.M. Pires \& N.T. Silva 4399 (IAN); rio Aripuanã, 59 $9^{\circ} 1^{\prime}$ N e $10^{\circ} 12^{\prime}$ S, 10/10/1973, C.C. Berg et al. s.n. (NYP 18413)*. S. induta - BRASIL: PIAUí: morro de Jurumenha, F.B. Ramalho 273 (RB)*. S. insignis - BRASIL: Pará: Belém, Instituto Agronômico do Norte, J.M. Pires 2632 (IAN)*; idem, mata da Cia. Pirelli, fazenda Uriboca, J.M. Pires 6820 (IAN); Paragominas, Itinga do Pará, M.G. Silva \& R.P. Bahia 3154 (HBR). S. juruana - BRASIL: ACRE: próximo à nascente do rio Macanhan, 1/9/1933, B.A. Krukoff s.n. (NY 5731)*. S. kanukuensis - BRASIL: PARÁ: Alto Tapajós, Missão Velha, W.A. Egler 973 (MG)*. S. miqueliana - BRASIL: AMAPÁ: cachoeira das Guaribas, W.A. Egler \& H.S. Irwin 46431 (IAN); idem, Rio Araguari, R.L. Fróes \& G.A. Black 27598 (IAN); AMAZONAS: rio Jari, monte Dourado, E. Oliveira 4339 (IAN)*. S. mosenii - BRASIL: RIo DE JANEIRO: Rio de Janeiro, Corcovado, A.P. Duarte 4950 (US)*. S. multiflora - BRASIL: AMAZONAS: São Paulo de Olivença, base do rio Solimões, B.A. Krukoff 8637 (NY)*; PARÁ: São Miguel do Guamá, D.A. Lima \& G.A. Black 48-3110 (IAN); Belém, estr. Providência-Japará, A. Ducke 1646 (NY); rio Guamá, beira do rio Irituia, R.L. Fróes 20600 (IAN). S. opacifolia - BRASIL: RondôNIA: Porto Velho, Vila Caneco, Mineração Jacundá, G. Vieira et al. 249 (MG)*. S. pachyphylla BRASIL: ACRE: Rio Branco, Camanié, J.G. Kuhlmann 726 (RB)*. S. solimonensis - COLÔMBIA: ANTIOQUIA: San Carlos, J.L. Zarucchi et al. 6739 (HUA)*. S. spectabilis - BRASIL: AmAZONAS: Esperança, lago do Genipapo, A. Ducke 1574 (IAN)*.

Os grãos de pólen foram acetolisados (Erdtman 1960), medidos até sete dias após sua preparação (Salgado-Labouriau 1973), foto e eletromicrografados. Nas amostras com 25 medidas, calculou-se a média aritmética $(\overline{\mathrm{x}})$; o desvio padrão da amostra (s); o desvio padrão da média ( $\left(\mathrm{s}_{\mathrm{x}}\right)$ o coeficiente de variabilidade (CV) e o intervalo de confiança a 95\% (Vieira 1981).

Foram realizadas, para cada espécie, somente dez medidas da abertura (comprimento e largura, excluída a margem) e da espessura da margem, bem como da exina (sexina e nexina) e dos diâmetros do pólen do material de comparação. A medida da exina foi feita sempre com o pólen em vista polar, na região mediana do mesocolpo. O teto e a nexina 1 foram medidos sempre que possível; foi difícil estabelecer a espessura da nexina 2, apesar de ser discernível, em algumas espécies. Nesses casos foi apenas calculada a média aritmética. A nomenclatura adotada segue Barth \& Melhem (1988) e Punt et al. (1999).

No presente trabalho, a área apertural foi considerada: "nãoproeminente" (quando a abertura não fica saliente, podendo destacar-se devido à espessura de suas margens); proeminente (quando a área apertural e a abertura ficam salientes devido ao espessamento da sexina e nexina 1 , conferindo à área apertural a aparência de um halo, dependendo do nível de focalização) e "muito-proeminente" (quando a área apertural e a abertura ficam destacadas em relação ao contorno do grão de pólen).

\section{Resultados}

As espécies de Salacia apresentaram grãos de pólen de tamanho médio (pequeno em $S$. kanukuensis, S. solimoensis e S. spectabilis); isopo- 
lares; oblato-esferoidais (prolato-esferoidais em $S$. duckei e S. kanukuensis); âmbito de forma variável (subcircular, subtriangular ou triangular); angulaperturados; área polar pequena (muito pequena em S. amplectens, S. bullata, S. miqueliana, S. mosenii e $S$. pachyphylla); 3-colporados; reticulados a microrreticulados (tabela 1).

Os colpos variam de longos a muito longos, estreitos, margem ornamentada; endoaberturas lalongadas, margem ornamentada. As margens dos cólporos, na maioria das espécies, são muito espessas (tabela 2); sob MEV, podem ser observadas as margens proeminentes dos cólporos de $S$. arborea (figura 10) e de $S$. crassifolia (figura 27). A área apertural é proeminente na maioria dos táxons, podendo se apresentar "não-proeminente" em: $S$. amplectens (figuras 1, 3), S. amygdalina (figura 5), S. duckei (figura 34), S. multiflora (figura 89) e $S$. pachyphylla (figuras 101, 106) ou "muito-proeminente" em $S$. crassifolia (figuras 26, 30), S. gigantea (figuras 40, 43), S. kanukuensis (figura 66), $S$. miqueliana (figuras 72, 77) e $S$. spectabilis (figuras 112, 113). Em S. miqueliana, a área apertural é tão proeminente que fica saliente em relação ao mesocolpo (figura 72). Apenas em S. juruana foram encontrados $2 \%$ de grãos de pólen 4-colporados.

A exina varia de microrreticulada a homobrocada ou heterobrocada: com lúmens menores nos pólos e próximo das aberturas ou somente próximo das aberturas (tabela 1). Em $S$. impressifolia (figura 45) e $S$. miqueliana (figura 72), em torno das aberturas e nos pólos, sob microscopia de luz, os diâmetros dos lúmens caracterizam uma ornamentação microrreticulada. Os microrretículos ou retículos possuem lúmens de contornos variáveis e muros ondulados devido a columelas proeminentes nos pontos de interseção dos lúmens (figuras 1, 17, 18, 20, 36, 53); sexina com camada infratectal simplescolumelada, mais espessa no mesocolpo e gradativamente mais fina próximo das aberturas. Nexina menos espessa que a sexina (tabela 2). As eletromicrografias dos grãos de pólen de $S$. amygdalina

Tabela 1. Ornamentação da sexina dos grãos de pólen de espécies de Salacia, sob microscopia de luz.

\begin{tabular}{|c|c|c|}
\hline Espécies & Características da sexina & Figuras \\
\hline S. amplectens & heterobrocada, lúmens menores apenas próximo das aberturas & $1-4$ \\
\hline S. amygdalina & heterobrocada, lúmens menores nos pólos e próximo das aberturas & $5-8$ \\
\hline S. arborea & heterobrocada, lúmens menores próximo das aberturas & $9-12$ \\
\hline S. bullata & heterobrocada, lúmens menores nos pólos e próximo das aberturas & $13-19$ \\
\hline S. calloneura & heterobrocada, lúmens menores próximo das aberturas & $20-24$ \\
\hline S. crassifolia & microrreticulada & $25-30$ \\
\hline S. duckei & heterobrocada, lúmens menores nos pólos e próximo das aberturas & $31-35$ \\
\hline S. elliptica & heterobrocada, lúmens menores próximo das aberturas & $36-39$ \\
\hline S. gigantea & homobrocada & $40-44$ \\
\hline S. impressifolia & heterobrocada, lúmens menores nos pólos e próximo das aberturas & $45-49$ \\
\hline S. induta & heterobrocada, lúmens menores nos pólos e próximo das aberturas & $50-52$ \\
\hline S. insignis & heterobrocada, lúmens menores nos pólos e próximo das aberturas & $53-57$ \\
\hline S. juruana & microrreticulada & $58-65$ \\
\hline S. kanukuensis & microrreticulada & $66-71$ \\
\hline S. miqueliana & heterobrocada, lúmens menores nos pólos e próximo das aberturas & $72-80$ \\
\hline S. mosenii & microrreticulada & $81-88$ \\
\hline S. multiflora & homobrocada & $89-94$ \\
\hline S. opacifolia & microrreticulada & $95-100$ \\
\hline S. pachyphylla & heterobrocada, lúmens menores próximo das aberturas & $101-106$ \\
\hline S. solimoensis & microrreticulada & $107-110$ \\
\hline S. spectabilis & heterobrocada, lúmens menores nos pólos e próximo das aberturas & $111-115$ \\
\hline
\end{tabular}


Tabela 2. Média aritmética $(\mathrm{em} \mu \mathrm{m})$ das medidas das aberturas e das camadas da exina dos grãos de pólen de espécies de Salacia $(\mathrm{n}=$ 10). Ex. = Exina total; Nex. = nexina; Nex. 1 ; Sex. $=$ Sexina; $* \mathrm{n}<10$.

\begin{tabular}{|c|c|c|c|c|c|c|c|c|c|}
\hline \multirow[t]{2}{*}{ Espécies } & \multicolumn{2}{|c|}{ Colpo } & \multicolumn{2}{|c|}{ Endoabertura } & \multicolumn{5}{|c|}{ Exina } \\
\hline & compr. x larg & margem & compr. $x$ larg & margem & Ex. & Nex. & Nex.1 & Sex. & Teto \\
\hline S. amplectens & $17,5 \times 1,6$ & 2,0 & $2,9 \times 4,9$ & 1,8 & 3,2 & 1,5 & 0,8 & 1,7 & 1,0 \\
\hline S. amygdalina & $20,7 \times 1,2$ & 1,6 & $2,8 \times 6,6$ & 1,1 & 2,6 & 1,0 & - & 1,6 & 1,0 \\
\hline S. arborea & $21,3 \times 1,0$ & 1,8 & $4,6 \times 5,0$ & 0,7 & 2,5 & 1,1 & - & 1,4 & 1,0 \\
\hline S. bullata & $16,3 \times 0,8$ & 1,4 & $2,4 \times 2,8$ & 1,2 & 3,0 & 1,0 & - & 2,0 & 1,2 \\
\hline S. calloneura & $22,0 \times 0,8$ & 1,8 & $2,7 \times 6,0$ & 1,5 & 3,5 & 1,0 & 0,8 & 2,5 & 1,9 \\
\hline S. crassifolia* & $19,0 \times 0,6$ & 1,0 & $2,4 \times 3,7$ & 0,8 & 2,3 & 1,0 & 0,8 & 1,3 & 0,8 \\
\hline S. duckei & $19,9 \times 0,8$ & 1,6 & $3,3 \times 4,0$ & 1,1 & 3,5 & 1,1 & 0,6 & 2,4 & 1,8 \\
\hline S. elliptica & $19,9 \times 1,0$ & 1,4 & $2,5 \times 4,4$ & 0,9 & 2,7 & 1,0 & 0,7 & 1,7 & 1,2 \\
\hline S. gigantea & $16,7 \times 0,6$ & 1,2 & $2,7 \times 3,8$ & 0,9 & 2,7 & 1,1 & 0,7 & 1,6 & 1,0 \\
\hline S. impressifolia & $22,6 \times 1,5$ & 2,1 & $3,7 \times 5,4$ & 0,7 & 3,0 & 1,3 & 0,7 & 1,7 & 1,1 \\
\hline S. induta & $19,1 \times 0,7$ & 1,2 & $2,4 \times 4,7$ & 0,9 & 2,7 & 1,2 & 0,6 & 1,5 & 1,0 \\
\hline S. insignis & $19,0 \times 0,9$ & 1,2 & $3,3 \times 4,1$ & 0,8 & 2,9 & 1,2 & 0,8 & 1,7 & 1,0 \\
\hline S. juruana & $21,4 \times 1,1$ & 1,9 & $2,2 \times 4,0$ & 0,8 & 2,5 & 1,2 & 0,7 & 1,3 & 0,8 \\
\hline S. kanukuensis* & $15,6 \times 0,6$ & 0,8 & $1,8 \times 3,4$ & 0,8 & 2,5 & 1,0 & 0,8 & 1,5 & 0,8 \\
\hline S. miqueliana & $19,8 \times 0,8$ & 1,5 & $2,0 \times 5,0$ & 0,9 & 2,8 & 1,0 & 0,7 & 1,8 & 1,2 \\
\hline S. mosenii & $18,7 \times 1,5$ & 1,8 & $3,6 \times 4,6$ & 1,8 & 3,6 & 1,4 & 0,9 & 2,2 & 1,4 \\
\hline S. multiflora & $21,0 \times 0,9$ & 1,3 & $3,5 \times 3,8$ & 1,0 & 2,9 & 1,2 & 1,0 & 1,7 & 1,2 \\
\hline S. opacifolia & $19,6 \times 0,7$ & 1,6 & $2,4 \times 3,7$ & 1,1 & 2,8 & 1,2 & 0,7 & 1,6 & 0,8 \\
\hline S. pachyphylla & $25,5 \times 1,0$ & 2,1 & $3,4 \times 4,9$ & 0,6 & 3,6 & 1,2 & 0,7 & 2,4 & 1,7 \\
\hline S. solimoensis & $17,3 \times 1,1$ & 1,2 & $3,5 \times 3,8$ & 0,9 & 2,3 & 1,0 & 0,8 & 1,3 & - \\
\hline S. spectabilis* & $12,8 \times 0,6$ & 0,7 & $2,0 \times 2,4$ & 0,7 & 2,4 & 1,0 & 0,7 & 1,2 & 0,7 \\
\hline
\end{tabular}

(figura 6), S. arborea (figura 10) e de S. multiflora (figura 93) mostram retículos com muros ondulados; em $S$. amplectens (figura 2) e S. mosenii (figura 85) a sexina parece perfurada; em S. elliptica (figura 37) os retículos têm muros altos, arredondados e entrelaçados em alguns pontos e em S. impressifolia (figura 47) a sexina é rugulado-reticulada, no mesocolpo; a área polar aparece como microrreticulada em $S$. bullata (figura 14), S. insignis (figura 55) e $S$. miqueliana (figura 76).

Nos espécimens de $S$. amygdalina e S. bullata foram encontrados grãos de pólen deformados (figuras 8,16$)$ com tendência a prolatos. Em S. duckei a figura 31 registra o tipo de grão de pólen mais freqüente para a espécie, tendo sido esta forma considerada para fins de mensuração apesar de existir, na amostragem examinada, uma pequena porcentagem (2\%) da forma oblata (figura 32).

Os espécimens de comparação das espécies de Salacia foram muito escassos, tendo sido comparados apenas os grãos de pólen de 11 táxons. Constatou-se que, com exceção dos grãos de pólen do espécimen de comparação de $S$. amplectens, os grãos de pólen das demais espécies mantiveram constantes o tamanho e a forma quando comparados com os dos respectivos materiais padrão (tabelas 3-6).

Chave polínica para separação das espécies brasileiras de Salacia

1. Grãos de pólen pequenos $(<25,0 \mu \mathrm{m})$

2. Grãos de pólen prolato-esferoidais

2. Grãos de pólen oblato-esferoidais

S. kanukuensis 
3. Exina microrreticulada . . . . . . . . . . . . . . . S. solimoensis

3. Exina heterobrocada com lúmens menores nos pólos e próximo

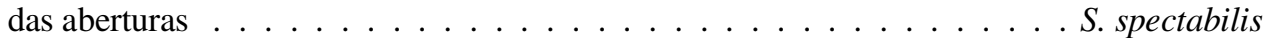

1. Grãos de pólen médios $(\geq 25,0 \mu \mathrm{m})$

4. Exina microrreticulada

5. Área polar muito pequena $\ldots \ldots \ldots \ldots \ldots \ldots$. mosenii

5. Área polar pequena . . . . . . . . . . . . . . . . S. crassifolia

S. juruana

S. opacifolia

4. Exina reticulada

6. Exina homobrocada

7. Área apertural "muito-proeminente" . . . . . . . . . . . . . . . gigantea

7. Área apertural "não-proeminente" . . . . . . . . . . . . . . S. multiflora

6. Exina heterobrocada

8. Lúmens menores próximos das aberturas

9. Área polar muito pequena; área apertural "não-proeminente" . . . . S. amplectens,

S. pachyphylla

9. Área polar pequena; área apertural proeminente . . . . . . . . . . . S. arborea

S. calloneura

S. elliptica

8. Lúmens menores próximos das aberturas e nos pólos

10. Área polar muito pequena

11. Área apertural proeminente; diâm. equatorial:

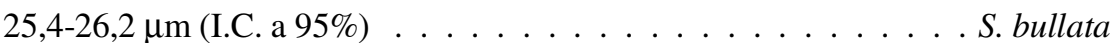

11. Área apertural "muito-proeminente"; diâm. equatorial: 28,0-28,8 $\mu \mathrm{m}$ (I.C. a 95\%) . . . . . . . . . . . . . . S. miqueliana

10. Área polar pequena

12. Prolato-esferoidais . . . . . . . . . . . . . . . . S. duckei

12. Oblato-esferoidais

13. Área apertural "não-proeminente" . . . . . . . . . . . S. amygdalina

13. Área apertural proeminente ou "muito-proeminente"

14. Área apertural "muito-proeminente" . . . . . . . . . S. impressifolia

14. Área apertural proeminente . . . . . . . . . . S. induta

S. insignis

\section{Discussão}

Os grãos de pólen das espécies de Salacia aqui estudadas foram caracterizados por apresentarem tamanho médio (exceto $S$. kanukuensis, $S$. solimoensis, $S$. spectabilis, que apresentaram tamanho pequeno), forma oblato-esferoidal (exceto S. duckei, S. kanukuensis, com forma prolato-esferoidal), área polar (na maioria, pequena) e no tipo da endoabertura lalongada. Do complexo de espécies estudadas, não se conseguiu separar $S$. crassifolia e $S$. juruana de $S$. opacifolia; $S$. amplectens de $S$. pachyphylla; $S$. arborea e $S$. calloneura de $S$. elliptica; $S$. induta de $S$. insignis utilizando-se as características polínicas. Os dados aqui obtidos confirmam as características genéricas apresentadas para $S$. erecta (Erdtman 1952) e $S$. staudtiana Loes. var. longuria N. Hallé (Hallé 1960).

A morfologia polínica dos grãos de pólen de $S$. bullata e $S$. amplectens, não confirma o posicionamento de Mennega (1984), quando reconheceu se- 

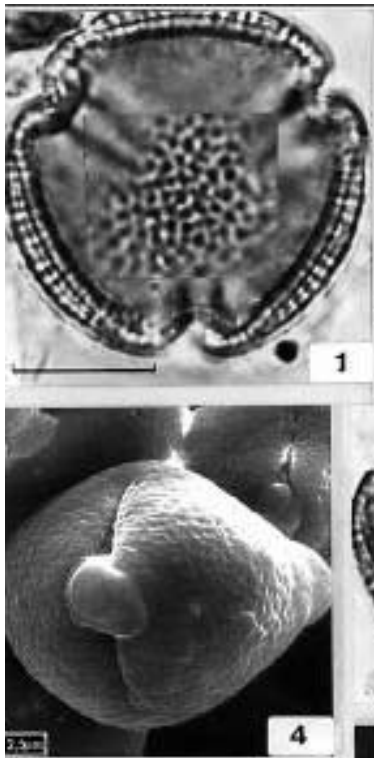

1
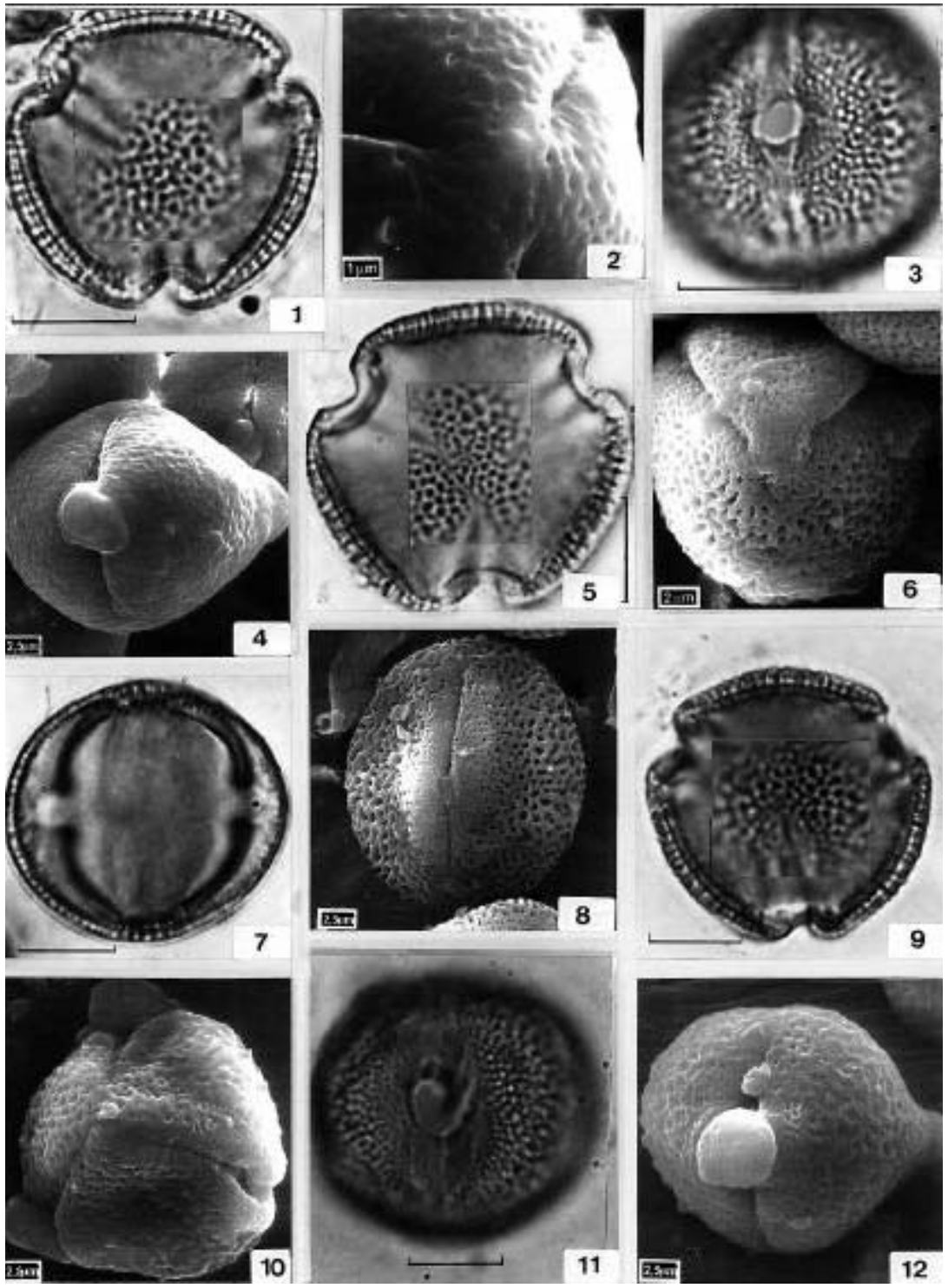

Figuras 1-12. Fotomicrografias e eletromicrografias dos grãos de pólen de espécies de Salacia. 1-4. S. amplectens. 1. corte óptico e superfície em vista polar; 2. detalhe da superfície em vista polar (MEV); 3. abertura em vista equatorial; 4. abertura e superfície em vista equatorial (MEV). 5-8. S. amygdalina. 5. corte óptico e superfície em vista polar; 6. superfície em vista polar (MEV); 7. contorno em vista equatorial; 8. abertura e superfície em vista equatorial (MEV). 9-12. S. arborea. 9. corte óptico e superfície em vista polar; 10. apocolpo e superfície em vista polar (MEV); 11. abertura em vista equatorial; 12. abertura e superfície em vista equatorial (MEV). Escala $=10 \mu \mathrm{m}$. 


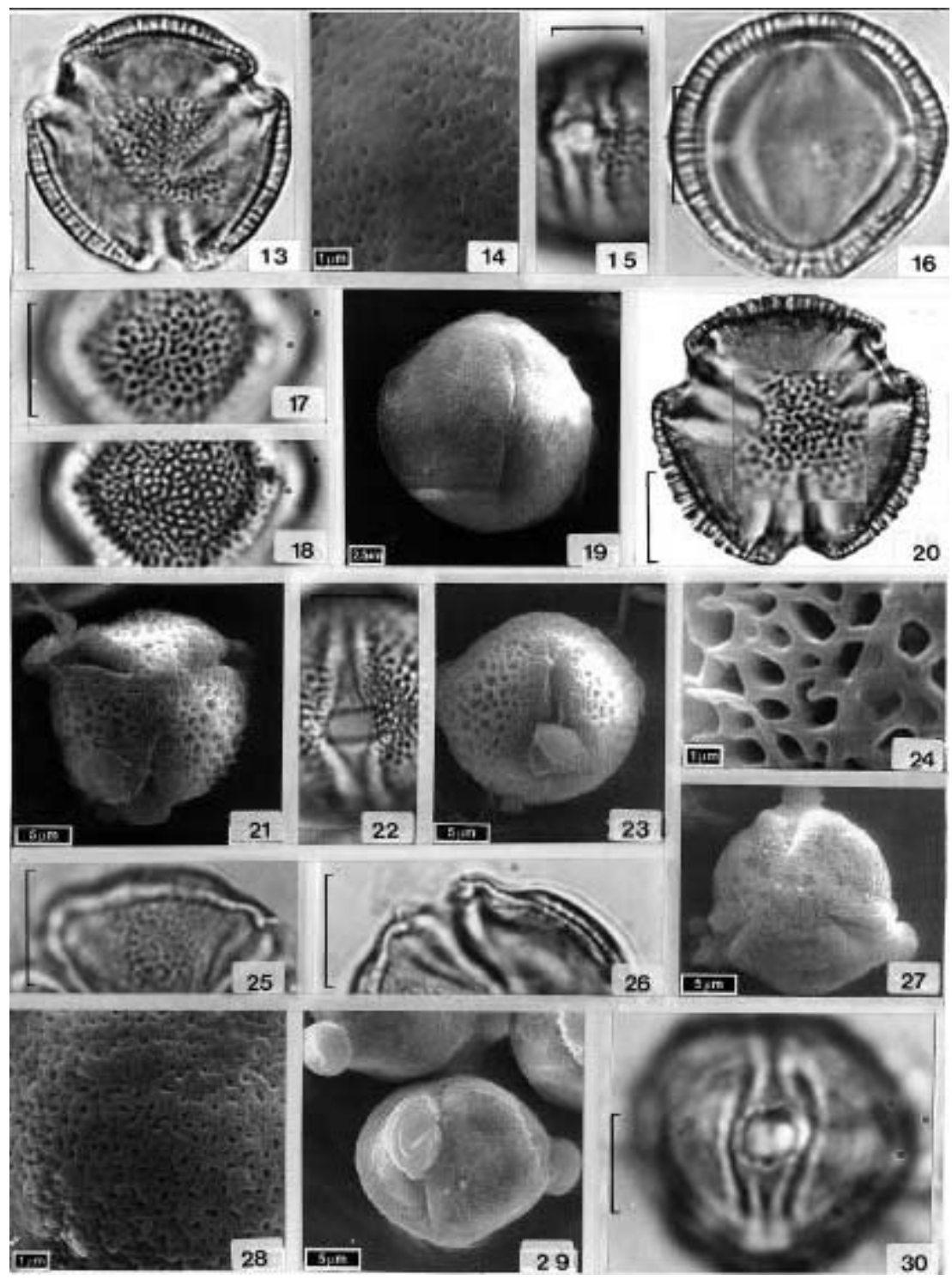

Figuras 13-30. Fotomicrografias e eletromicrografias dos grãos de pólen de espécies de Salacia. 13-18. S. bullata. 13. corte óptico e superfície em vista polar; 14. detalhe da superfície em vista polar (MEV); 15. abertura em vista equatorial; 16. corte óptico em vista equatorial; 17-18. L.O.; 19. abertura e superfície em vista equatorial (MEV). 20-24. S. calloneura. 20. corte óptico e superfície em vista polar; 21. apocolpo e superfície em vista polar (MEV); 22. detalhe da abertura em vista equatorial; 23. abertura e superfície em vista equatorial (MEV); 24. detalhe da superfície em vista equatorial (MEV). 25-30. S. crassifolia. 25. detalhe da superfície em vista polar; 26. detalhe em corte óptico (vista polar); 27. apocolpo e superfície em vista polar (MEV); 28. detalhe da superfície em vista polar; 29. abertura e superfície em vista equatorial (MEV); 30. abertura em vista equatorial. Escala $=10 \mu \mathrm{m}$. 


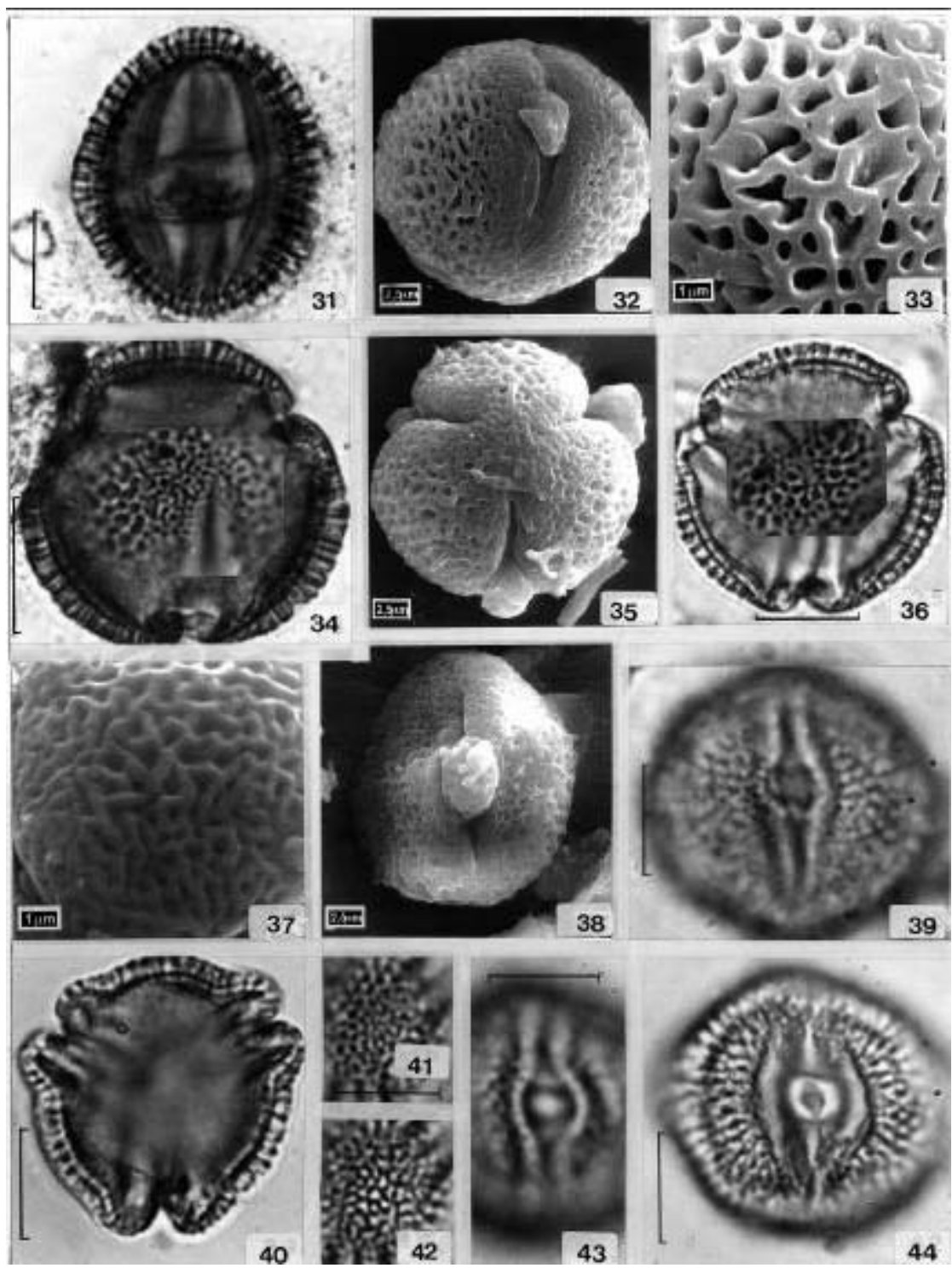

Figuras 31-44. Fotomicrografias e eletromicrografias dos grãos de pólen de espécies de Salacia.31-35. S. duckei. 31. contorno em vista equatorial; 32. abertura e superfície em vista equatorial (MEV); 33. detalhe da superfície em vista equatorial (MEV); 34. corte óptico e superfície em vista polar; 35. apocolpo e superfície em vista polar (MEV); 36-39. S. elliptica. 36. corte óptico e superfície em vista polar; 37. detalhe da superfície em vista polar (MEV); 38. abertura e superfície em vista equatorial (MEV); 39. abertura em vista equatorial. 40-44. S. gigantea. 40. corte óptico em vista polar (MEV); 41-42. L.O.; 43. abertura em vista equatorial; 44. abertura em vista equatorial. Escala $=10 \mu \mathrm{m}$. 


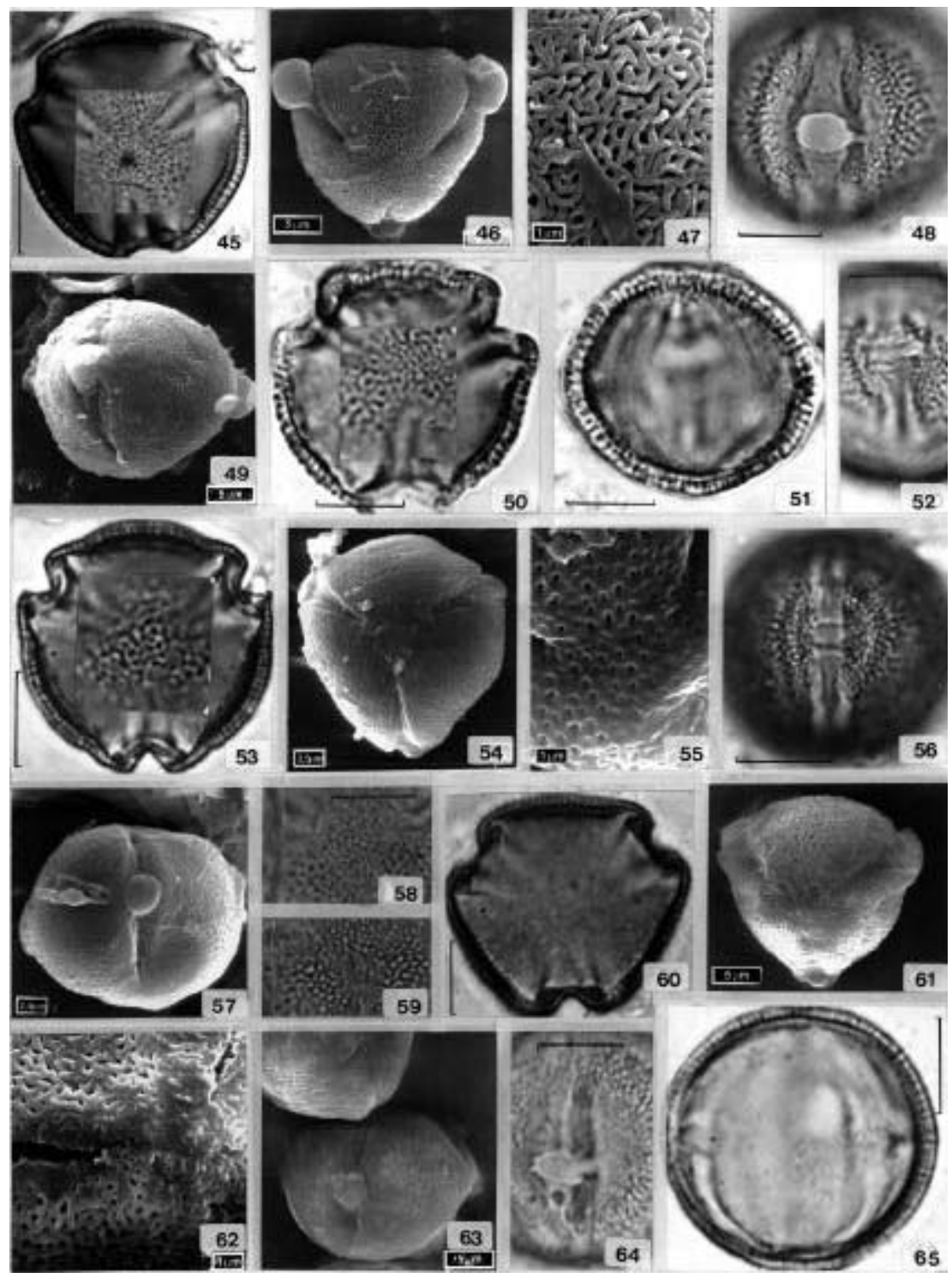

Figuras 45-65. Fotomicrografias e eletromicrografias dos grãos de pólen de espécies de Salacia. 45-49. S. impressifolia. 45. corte óptico e superfície em vista polar; 46. apocolpo e superfície em vista polar (MEV); 47. detalhe da superfície em vista polar (MEV); 48. abertura em vista equatorial; 49. abertura e superfície em vista equatorial (MEV). 50-52. S. induta. 50. corte óptico e superfície em vista polar; 51. contorno em vista equatorial; 52. detalhe da abertura em vista equatorial. 53-57. S. insignis. 53. corte óptico e superfície em vista polar; 54. apocolpo e superfície em vista polar (MEV); 55. detalhe da superfície em vista polar (MEV); 56. abertura em vista equatorial; 57. abertura e superfície em vista equatorial (MEV). 58-65. S. juruana. 58-59. L.O.; 60. corte óptico em vista polar; 61. apocolpo e superfície em vista polar (MEV); 62. detalhe da superfície em vista polar (MEV); 63. abertura e superfície em vista equatorial (MEV); 64. detalhe da abertura em vista equatorial; 65 . corte óptico em vista equatorial. Escala $=10 \mu \mathrm{m}$. 


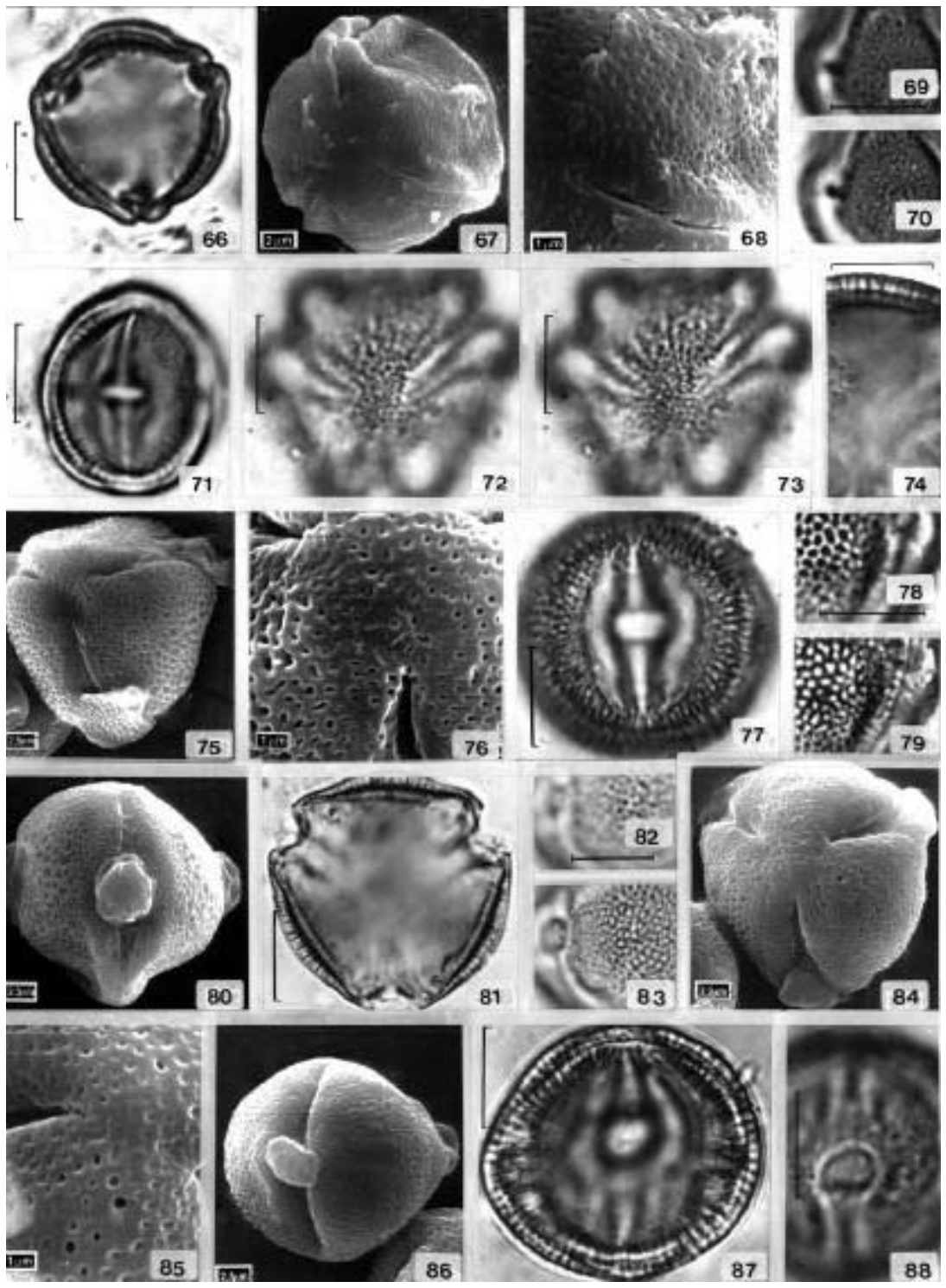

Figuras 66-88. Fotomicrografias e eletromicrografias dos grãos de pólen de espécies de Salacia. 66-71. S. kanukuensis. 66. corte óptico em vista polar; 67. apocolpo e superfície em vista polar (MEV); 68. detalhe da superfície em vista polar (MEV); 69-70. L.O.; 71. abertura em vista equatorial. 72-80. S. miqueliana. 72-73. L.O.; 74. detalhe de corte óptico em vista polar; 75. apocolpo e superfície em vista polar (MEV); 76. detalhe da superfície em vista polar (MEV); 77. abertura em vista equatorial; 78-79. L.O.; 80. abertura e superfície em vista equatorial (MEV). 81-88. S. mosenii. 81. corte óptico em vista polar; 82-83. L.O.; 84. apocolpo e superfície em vista polar (MEV); 85. detalhe da superfície em vista polar (MEV); 86. abertura e superfície em vista equatorial (MEV); 87. contorno em vista equatorial; 88. detalhe da abertura em vista equatorial. Escala $=10 \mu \mathrm{m}$. 
Tabela 3. Medidas dos grãos de pólen de espécies de Salacia, em vista equatorial $(\mathrm{n}=25)$.

\begin{tabular}{|c|c|c|c|c|c|c|c|c|c|}
\hline \multirow[b]{2}{*}{ Espécies } & \multirow[b]{2}{*}{$\mathrm{P} / \mathrm{E}$} & \multicolumn{4}{|c|}{ Diâmetro polar } & \multicolumn{4}{|c|}{ Diâmetro equatorial } \\
\hline & & $\begin{array}{c}\text { Faixa de } \\
\text { Variação }(\mu \mathrm{m})\end{array}$ & $\bar{x} \pm s_{x}^{-}(\mu m)$ & $\mathrm{s}(\mu \mathrm{m})$ & $\mathrm{CV} \%$ & $\begin{array}{c}\text { Faixa de } \\
\text { variação }(\mu \mathrm{m})\end{array}$ & $\bar{x} \pm s_{x}^{-}(\mu m)$ & $\mathrm{s}(\mu \mathrm{m})$ & $\mathrm{CV} \%$ \\
\hline S. amplectens & 0,91 & $23,2-26,4$ & $24,8 \pm 0,1$ & 0,6 & 2,6 & $25,2-29,8$ & $27,3 \pm 0,2$ & 1,1 & 4,0 \\
\hline S. amygdalina & 0,94 & $24,9-30,8$ & $28,4 \pm 0,2$ & 1,1 & 3,9 & $26,2-32,9$ & $30,1 \pm 0,2$ & 1,2 & 3,8 \\
\hline S. arborea & 0,96 & $25,7-30,7$ & $28,2 \pm 0,2$ & 1,2 & 4,2 & $25,1-32,1$ & $29,4 \pm 0,2$ & 1,2 & 4,1 \\
\hline S. bullata & 0,95 & $22,8-25,4$ & $23,8 \pm 0,2$ & 0,9 & 3,7 & $23,5-28,8$ & $25,8 \pm 0,2$ & 0,9 & 3,5 \\
\hline S. calloneura & 0,95 & $27,1-31,5$ & $29,0 \pm 0,2$ & 1,1 & 3,8 & $28,9-32,9$ & $30,5 \pm 0,2$ & 0,9 & 3,0 \\
\hline S. crassifolia & 0,95 & $23,5-28,5$ & $25,7 \pm 0,2$ & 1,0 & 3,8 & $25,1-29,1$ & $27,1 \pm 0,2$ & 1,2 & 4,4 \\
\hline S. duckei & 1,13 & $29,1-34,2$ & $31,2 \pm 0,2$ & 0,9 & 2,8 & $25,3-30,2$ & $27,6 \pm 0,2$ & 0,8 & 2,9 \\
\hline S. elliptica & 0,92 & $24,2-27,2$ & $25,6 \pm 0,2$ & 0,7 & 2,6 & $25,4-30,2$ & $27,7 \pm 0,2$ & 1,1 & 3,8 \\
\hline S. gigantea & 0,92 & $22,3-26,1$ & $23,9 \pm 0,2$ & 1,0 & 4,1 & $23,8-27,9$ & $26,1 \pm 0,2$ & 1,0 & 3,8 \\
\hline S. impressifolia & 0,90 & $27,0-30,6$ & $28,8 \pm 0,2$ & 0,9 & 3,2 & $29,2-34,2$ & $32,0 \pm 0,2$ & 1,3 & 3,9 \\
\hline S. induta & 0,89 & $25,1-29,2$ & $27,2 \pm 0,2$ & 1,1 & 4,1 & $27,6-33,9$ & $30,5 \pm 0,1$ & 1,2 & 3,8 \\
\hline S. insignis & 0,92 & $22,6-27,2$ & $25,3 \pm 0,2$ & 0,8 & 3,0 & $25,9-29,5$ & $27,6 \pm 0,2$ & 1,0 & 3,8 \\
\hline S. juruana & 0,92 & $26,7-31,0$ & $28,7 \pm 0,2$ & 1,2 & 4,2 & $27,4-33,2$ & $31,2 \pm 0,2$ & 1,1 & 3,7 \\
\hline S. kanukensis & 1,09 & $20,5-25,8$ & $22,3 \pm 0,2$ & 1,0 & 4,5 & $18,7-22,0$ & $20,4 \pm 0,2$ & 0,9 & 4,4 \\
\hline S. miqueliana & 0,91 & $24,3-27,7$ & $25,9 \pm 0,2$ & 1,1 & 4,4 & $26,5-30,4$ & $28,4 \pm 0,2$ & 1,1 & 4,0 \\
\hline S. mosenii & 0,93 & $21,2-27,0$ & $24,7 \pm 0,2$ & 1,1 & 4,4 & $23,2-29,6$ & $26,5 \pm 0,2$ & 1,3 & 4,3 \\
\hline S. multiflora & 0,96 & $25,9-33,4$ & $29,7 \pm 0,2$ & 1,2 & 4,0 & $28,4-33,9$ & $30,9 \pm 0,2$ & 1,1 & 3,5 \\
\hline S. opacifolia & 0,94 & $23,6-27,0$ & $25,2 \pm 0,1$ & 0,6 & 2,3 & $24,9-29,1$ & $26,8 \pm 0,1$ & 0,7 & 2,4 \\
\hline S. pachyphylla & 0,98 & $31,7-35,8$ & $33,3 \pm 0,2$ & 1,1 & 3,3 & $31,9-36,1$ & $33,9 \pm 0,3$ & 1,3 & 3,8 \\
\hline S. solimoensis & 0,88 & $19,6-23,2$ & $20,9 \pm 0,2$ & 1,0 & 4,5 & $20,9-26,2$ & $23,8 \pm 0,2$ & 1,0 & 4,4 \\
\hline S. spectabilis & 0,92 & $18,1-21,3$ & $20,1 \pm 0,1$ & 0,6 & 2,8 & $19,5-23,1$ & $21,8 \pm 0,1$ & 0,7 & 3,1 \\
\hline
\end{tabular}

melhanças entre essas duas espécies; no presente estudo a chave polínica mostra que $S$. amplectens e $S$. pachyphylla estão mais próximas de $S$. calloneura, $S$. arborea e $S$. elliptica, enquanto que em $S$. bullata, os grãos de pólen possuem características que a aproximam mais de $S$. miqueliana. Nota-se, ainda, que do ponto de vista palinológico há a afinidade apontada por Rizzini (1976) entre $S$. induta e $S$. amygdalina.

Segundo Smith (1940), pela característica do disco nectarífero, duas espécies de Salacia pertencentes ao grupo Crassifoliae ( $S$. crassifolia e $S$. glomerata) podem estar relacionadas com dois outros gêneros de Hippocrateaceae (Tontelea Aubl. e Peritassa Miers). No entanto, estas espécies mostram a deiscência da antera típica do grupo Ellipticae ou seja, própria do gênero Salacia. Smith (1940) comenta ainda que a existência dessas duas espécies de Crassifoliae poderia indicar um enfraquecimento do "status" dos gêneros Peritassa e Tontelea porém, para o autor, estes são gêneros coerentes, estáveis e afins, apesar da forma transicional do disco nectarífero. 
Tabela 4. Medidas dos grãos de pólen de espécies de Salacia, em vista polar: diâmetro equatorial $(\mathrm{n}=25)$; lado da apocolpia LA e índice da área polar IAP $(\mathrm{n}=10)$.

\begin{tabular}{|c|c|c|c|c|c|c|}
\hline \multirow[b]{2}{*}{ Espécies } & \multicolumn{4}{|c|}{ Diâmetro equatorial } & \multirow{2}{*}{$\begin{array}{l}\text { LA } \bar{x} \\
(\mu \mathrm{m})\end{array}$} & \multirow{2}{*}{$\begin{array}{c}\text { I } \\
\text { Ap }\end{array}$} \\
\hline & Faixa de variação $(\mu \mathrm{m})$ & $\bar{x} \pm s_{x}(\mu m)$ & $\mathrm{s}(\mu \mathrm{m})$ & $\mathrm{CV} \%$ & & \\
\hline S. amplectens & $23,6-27,6$ & $25,3 \pm 0,1$ & 0,6 & 2,6 & 5,9 & 0,23 \\
\hline S. amygdalina & $24,2-30,4$ & $28,5 \pm 0,2$ & 1,3 & 4,4 & 7,3 & 0,26 \\
\hline S. arborea & $24,3-31,0$ & $28,5 \pm 0,2$ & 1,2 & 4,4 & 7,4 & 0,26 \\
\hline S. bullata & $25,0-28,8$ & $27,0 \pm 0,1$ & 0,6 & 2,3 & 6,5 & 0,24 \\
\hline S. calloneura & $27,8-32,8$ & $29,4 \pm 0,2$ & 1,2 & 3,9 & 8,3 & 0,28 \\
\hline S. crassifolia & $25,2-29,6$ & $27,1 \pm 0,2$ & 0,8 & 2,8 & 9,4 & 0,37 \\
\hline S. duckei & $25,2-30,3$ & $27,3 \pm 0,2$ & 0,8 & 3,0 & 9,4 & 0,34 \\
\hline S. elliptica & $23,8-27,8$ & $26,5 \pm 0,2$ & 1,0 & 3,6 & 7,4 & 0,28 \\
\hline S. gigantea & $23,1-29,1$ & $25,4 \pm 0,2$ & 1,1 & 4,4 & 7,9 & 0,31 \\
\hline S. impressifolia & $28,9-33,5$ & $31,1 \pm 0,2$ & 1,0 & 3,3 & 8,2 & 0,26 \\
\hline S. induta & $25,9-30,0$ & $27,9 \pm 0,2$ & 1,1 & 3,8 & 8,9 & 0,32 \\
\hline S. insignis & $26,6-30,6$ & $27,9 \pm 0,2$ & 1,2 & 4,4 & 8,7 & 0,31 \\
\hline S. juruana & $27,1-32,9$ & $30,2 \pm 0,2$ & 1,1 & 3,8 & 9,0 & 0,30 \\
\hline S. kanukuensis & $19,8-22,5$ & $21,1 \pm 0,2$ & 0,8 & 4,0 & 5,8 & 0,28 \\
\hline S. miqueliana & $23,7-27,2$ & $25,8 \pm 0,2$ & 0,9 & 3,5 & 6,0 & 0,23 \\
\hline S. mosenii & $25,0-30,6$ & $26,5 \pm 0,2$ & 1,2 & 4,4 & 6,6 & 0,24 \\
\hline S. multiflora & $28,0-32,6$ & $29,8 \pm 0,2$ & 1,1 & 3,8 & 9,6 & 0,32 \\
\hline S. opacifolia & $24,4-29,0$ & $26,6 \pm 0,2$ & 0,8 & 2,8 & 9,1 & 0,34 \\
\hline S. pachyphylla & $30,0-33,9$ & $32,5 \pm 0,2$ & 1,2 & 3,6 & 7,5 & 0,23 \\
\hline S. solimoensis & $21,9-25,2$ & $23,3 \pm 0,2$ & 1,0 & 4,4 & 6,2 & 0,27 \\
\hline S. spectabilis & $19,6-23,5$ & $21,7 \pm 0,1$ & 0,6 & 2,9 & 6,8 & 0,31 \\
\hline
\end{tabular}

O estudo palinológico permite concordar com Smith (1940) pois os grãos de pólen encontrados na maioria das espécies de Salacia são distintos dos de Peritassa (Gonçalves-Esteves 1994) e de Tontelea (Gonçalves-Esteves \& Melhem 1998).

Macbride (1951) transferiu algumas espécies de Tontelea "sensu" Smith (1940) para Salacia. O confronto dos resultados aqui obtidos para Salacia com os encontrados para Tontelea em Gonçalves-Esteves \& Melhem (1998) mostra que os grãos de pólen de Salacia são, predominantemente, de tamanho médio, oblato-esferoidais e reticulados (tabela 1), enquanto em Tontelea predominam grãos de pólen pequenos, suboblatos a oblato-esferoidais e microrreticulados.

Para Rasoarimalala et al. (1982), o pólen de Salacia é caracterizado pela presença de exina reticulada, simplescolumelada e malhas muito desiguais, enquanto que pólen com lúmen muito reduzido do tipo microrreticulado representaria outros táxons da família. Os dados aqui obtidos sob microscópio de luz e eletrônico de varredura não confirmam esse posicionamento já que foram reconhecidos grãos de pólen homorreticulados e microrreticulados, inclusive em Salacia. 
Tabela 5. Intervalo de confiança a 95\% dos diâmetros dos grãos de pólen de espécies de Salacia $(\mathrm{n}=25)$. DP: diâmetro polar; DE: diâmetro equatorial.

\begin{tabular}{|c|c|c|c|}
\hline \multirow[t]{2}{*}{ Espécies } & \multicolumn{2}{|c|}{ Vista equatorial } & \multirow{2}{*}{$\frac{\text { Vista polar }}{\mathrm{DE}(\mu \mathrm{m})}$} \\
\hline & $\mathrm{DP}(\mu \mathrm{m})$ & $\mathrm{DE}(\mu \mathrm{m})$ & \\
\hline S. amplectens & $24,6-25,0$ & $26,9-27,7$ & $25,1-25,5$ \\
\hline S. amygdalina & $28,0-28,8$ & $29,7-30,5$ & $28,1-28,9$ \\
\hline S. arborea & $27,8-28,6$ & $29,0-29,8$ & $28,1-28,9$ \\
\hline S. bullata & $23,4-24,2$ & $25,4-26,2$ & $26,8-27,2$ \\
\hline S. calloneura & $28,6-29,4$ & $30,1-30,9$ & $29,0-29,8$ \\
\hline S. crassifolia & $25,3-26,1$ & $26,7-27,5$ & $26,7-27,5$ \\
\hline S. duckei & $30,8-31,6$ & $27,2-28,0$ & $26,9-27,7$ \\
\hline S. elliptica & $25,2-26,0$ & $27,3-28,1$ & $26,1-26,9$ \\
\hline S. gigantea & $23,5-24,3$ & $25,7-26,5$ & $25,0-25,8$ \\
\hline S. impressifolia & $28,4-29,2$ & $31,6-32,4$ & $30,7-31,5$ \\
\hline S. induta & $26,8-27,6$ & $30,3-30,7$ & $27,5-28,3$ \\
\hline S. insignis & $24,9-25,7$ & $27,2-28,0$ & $27,5-28,3$ \\
\hline S. juruana & $28,3-29,1$ & $30,8-31,6$ & $29,8-30,6$ \\
\hline S. kanukuensis & $21,9-22,7$ & $20,0-20,8$ & $20,7-21,5$ \\
\hline S. miqueliana & $25,5-26,3$ & $28,0-28,8$ & $25,4-26,2$ \\
\hline S. mosenii & $24,3-25,1$ & $26,1-26,9$ & $26,1-26,9$ \\
\hline S. multiflora & $29,3-30,1$ & $30,5-31,3$ & $29,4-30,2$ \\
\hline S. opacifolia & $25,0-25,4$ & $26,6-27,0$ & $26,2-27,0$ \\
\hline S. pachyphylla & $32,9-33,7$ & $33,3-34,5$ & $32,1-32,9$ \\
\hline S. solimoensis & $20,5-21,3$ & $23,4-24,2$ & $22,9-23,7$ \\
\hline S. spectabilis & $19,9-20,3$ & $21,6-22,0$ & $21,5-21,9$ \\
\hline
\end{tabular}

O pólen, quando considerado no conjunto de seus atributos, revelou-se um caráter diagnóstico importante, principalmente em nível específico onde, além do tipo de área apertural e da ornamentação da exina, caracteres como a forma e as classes de tamanho mostraram-se constantes para cada espécie, tomando-se por base os resultados obtidos nos vários espécimens examinados para cada táxon.

As características dos grãos de pólen das espécies de Salacia não formaram conjuntos distintos que permitissem enquadrá-los nas divisões feitas por Smith (1940), não se oferecendo assim, um suporte palinológico à orientação taxonômica desse autor no que se refere aos grupos estribados apenas em caracteres macromorfológicos.
Tabela 6. Forma (P/E) e média aritmética $(\mathrm{em} \mu \mathrm{m})$ das medidas dos diâmetros polar (DP) e equatorial (DE) dos grãos de pólen de espécies de Salacia, dos materiais de comparação $(\mathrm{n}=10)$.

\begin{tabular}{|c|c|c|c|}
\hline Espécies & DP & $\mathrm{DE}$ & $\mathrm{P} / \mathrm{E}$ \\
\hline \multicolumn{4}{|l|}{ S. amplectens } \\
\hline B. Maguire 24717 & $18,5^{*}$ & $20,3^{*}$ & 0,91 \\
\hline \multicolumn{4}{|l|}{ S. amygdalina } \\
\hline Markgraf 10195 & 27,9 & 30,6 & 0,91 \\
\hline \multicolumn{4}{|l|}{ S. arborea } \\
\hline Riedel 1086 & 26,1 & 27,3 & 0,96 \\
\hline \multicolumn{4}{|l|}{ S. bullata } \\
\hline N.T. Silva s.n. & 24,9 & 27,9 & 0,89 \\
\hline C.S. Rosário et al 1143 & $24,2^{*}$ & $26,2 *$ & 0,92 \\
\hline \multicolumn{4}{|l|}{ S. calloneura } \\
\hline C.A. Cid et al. s.n. & $27,5^{*}$ & $29,0 *$ & 0,95 \\
\hline \multicolumn{4}{|l|}{ S. crassifolia } \\
\hline J.R. Pirani et al. s.n. & 24,9 & 25,2 & 0,99 \\
\hline B. Maguire et al. s.n. & 26,9 & 29,0 & 0,93 \\
\hline \multicolumn{4}{|l|}{ S. elliptica } \\
\hline H.S. Irwin et al. s.n. & 27,2 & 28,9 & 0,94 \\
\hline L.C. de Oliveira Fo 11 & 27,1 & 27,8 & 0,98 \\
\hline E.L. Taylor et al. s.n. & 27,0 & 29,1 & 0,93 \\
\hline Reitz \& Klein 1865 & 26,5 & 27,0 & 0,98 \\
\hline Glaziou 13582 & 26,5 & 28,8 & 0,92 \\
\hline \multicolumn{4}{|l|}{ S. impressifolia } \\
\hline G.T. Prance et al. s.n. & 30,5 & 32,2 & 0,95 \\
\hline J.M. Pires et al. 1184 & 29,0 & 32,2 & 0,90 \\
\hline R.E. Schultes e F. López s.n. & 30,5 & 34,0 & 0,90 \\
\hline J.M. Pires 3993 & 30,0 & 32,9 & 0,91 \\
\hline J.M. Pires e N.T. Silva 4399 & 32,5 & 36,0 & 0,90 \\
\hline \multicolumn{4}{|l|}{ S. insignis } \\
\hline J.M. Pires 6820 & 27,0 & 29,4 & 0,92 \\
\hline M.G. Silva e R.P. Bahia 3154 & 22,9 & 26,0 & 0,88 \\
\hline \multicolumn{4}{|l|}{ S. miqueliana } \\
\hline W.A. Egler e H.S. Irwin 46431 & 25,8 & 29,2 & 0,88 \\
\hline R.L. Fróes e G.A. Black 27598 & 27,5 & 30,2 & 0,91 \\
\hline \multicolumn{4}{|l|}{ S. multiflora } \\
\hline Dárdano e Black 48-3110 & $29,2^{*}$ & $31,5^{*}$ & 0,93 \\
\hline Ducke 1646 & $30,0^{*}$ & $31,2^{*}$ & 0,96 \\
\hline J.M. Pires 3122 & 28,6 & 31,0 & 0,92 \\
\hline R.L. Fróes 20600 & 31,2 & 33,1 & 0,94 \\
\hline
\end{tabular}



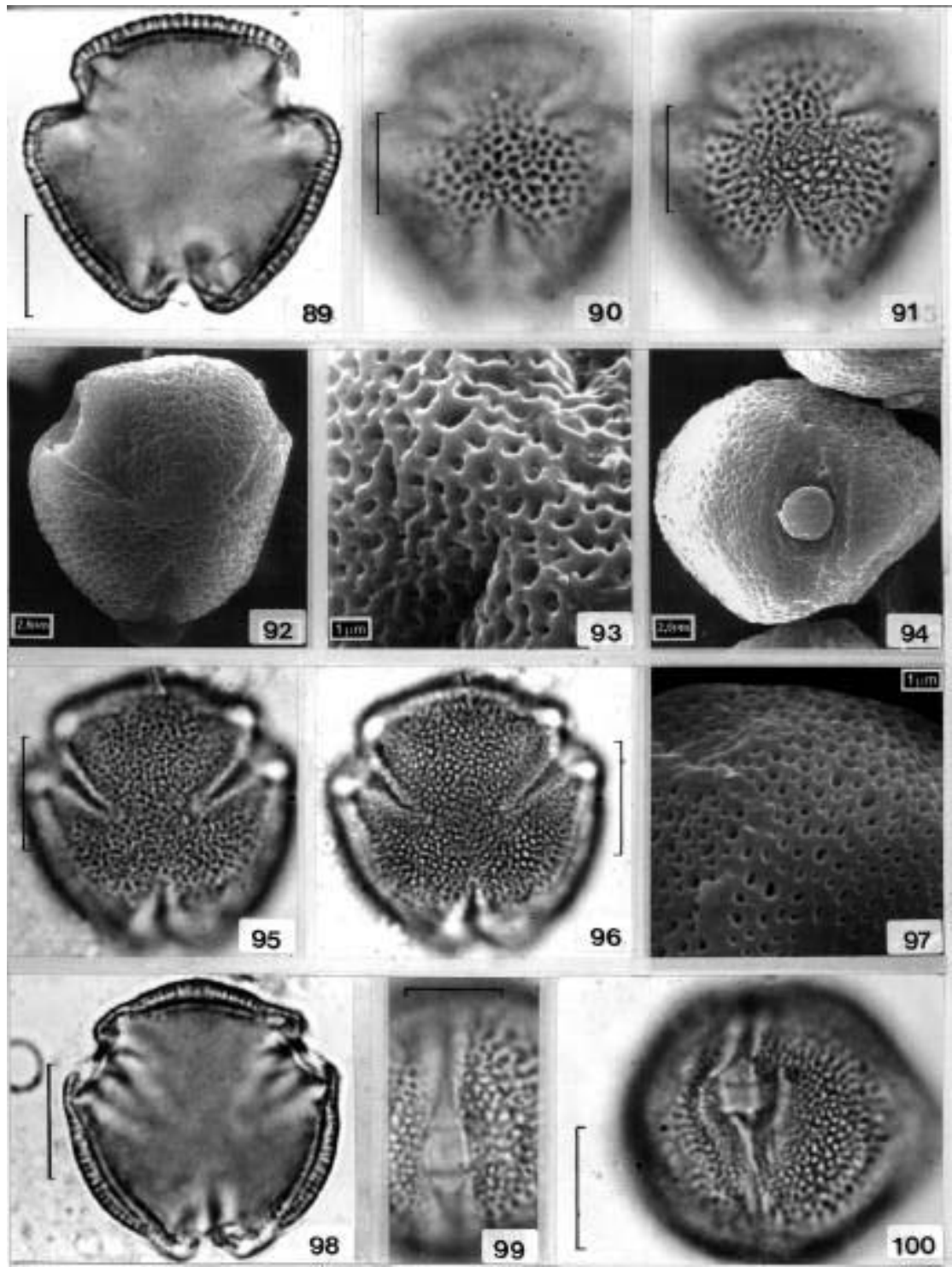

Figuras 89-100. Fotomicrografias e eletromicrografias dos grãos de pólen de espécies de Salacia. 89-94. S. multiflora. 89. corte óptico em vista polar; 90-91. L.O.; 92. apocolpo e superfície em vista polar; 93. detalhe da superfície em vista polar (MEV); 94. abertura e superfície em vista equatorial (MEV). 95-100. S. opacifolia. 95-96. L.O.; 97. detalhe da superfície em vista polar (MEV); 98. corte óptico em vista polar; 99. vista equatorial; 100. abertura em vista equatorial. Escala $=10 \mu \mathrm{m}$. 


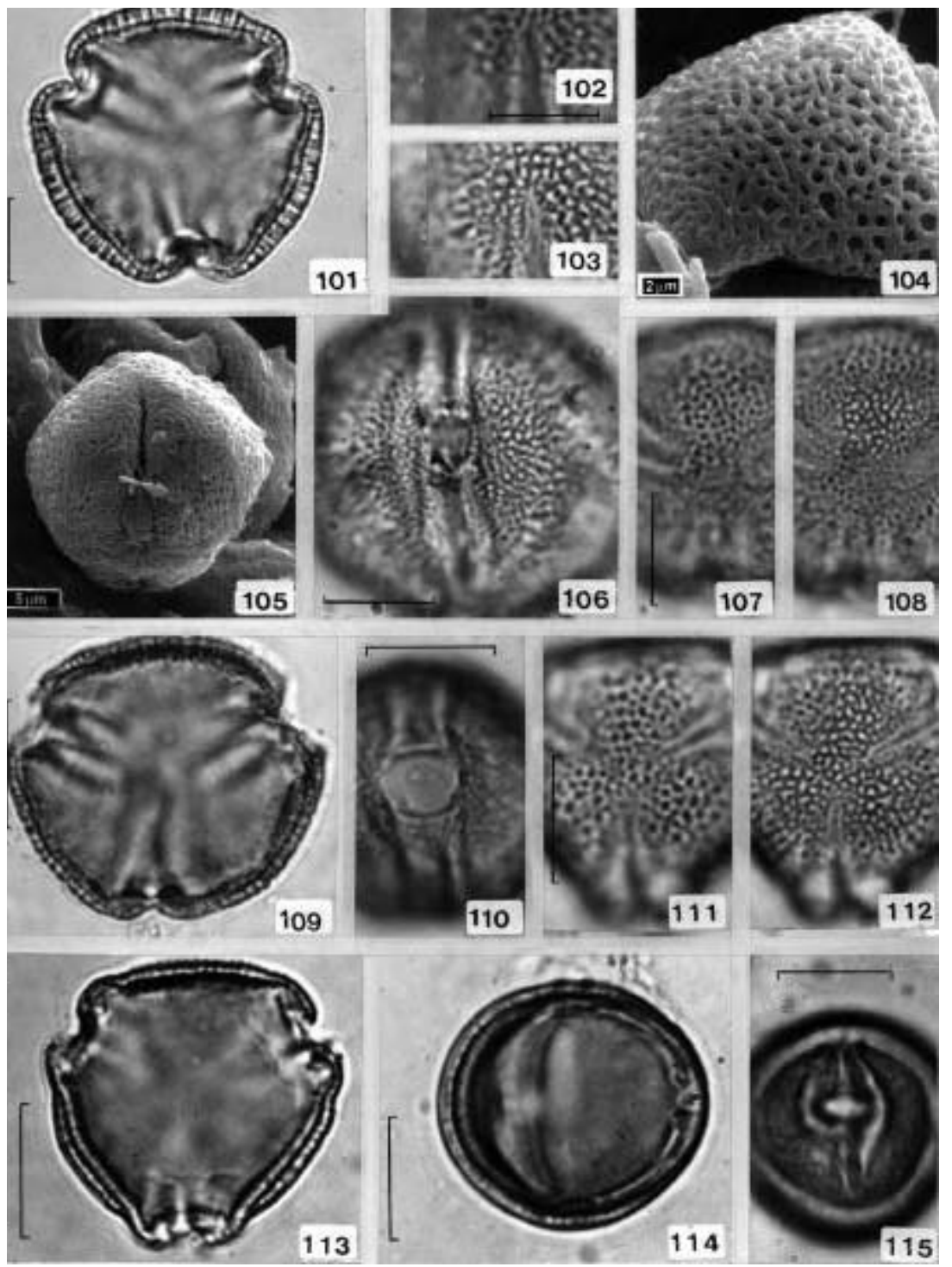

Figuras 101-115. Fotomicrografias e eletromicrografias dos grãos de pólen de espécies de Salacia. 101-106. S. pachyphylla. 101. corte óptico em vista polar; 102-103. L.O.; 104. detalhe da superfície em vista polar (MEV); 105. abertura e superfície em vista equatorial (MEV); 106. abertura em vista equatorial. 107-110. S. solimonensis. 107-108. L.O.; 109. corte óptico em vista polar; 110. detalhe da abertura em vista equatorial. 111-115. S. spectabilis. 111-112. L.O.; 113. corte óptico em vista polar; 114. contorno em vista equatorial; 115. abertura em vista equatorial. Escala $=10 \mu \mathrm{m}$. 
Agradecimentos - Ao Laboratório de Microscopia Eletrônica da Universidade de Brasília e à MSc. Maria de Fátima Lopes (PUCRio), por fornecerem condições de trabalho para a obtenção de eletromicrografias; ao CNPq pelo apoio a T. S. Melhem através de Bolsa de Produtividade Científica.

\section{Referências bibliográficas}

BARTH, O.M. \& MELHEM, T.S. 1988. Glossário ilustrado de palinologia. Editoria da Universidade Estadual de Campinas, Campinas.

BENTHAM, G. \& HOOKER, J.D. 1862. Hippocrateae. In Genera plantarum. A. Black, William Pamplin, Lovell Reeve \& Co., Williams \& Norgate eds., London, 1:369-370.

ERDTMAN, G. 1952. Pollen morphology and plant taxonomy Angiosperms. Almqvist \& Wiksell, Stockholm.

ERDTMAN, G. 1960. The acetolysis method. A revised description. Svensk Botanisk Tidskrift 54:561-564.

GONÇALVES-ESTEVES, V. 1994. Estudo palinotaxonômico da família Hippocrateaceae Juss. Tese de doutorado, Universidade de São Paulo, São Paulo.

GONÇALVES-ESTEVES, V. \& MELHEM, T.S. 1998. Palinotaxonomia de espécies brasileiras de Tontelea Aubl. (Hippocrateaceae Juss.). Polibotánica 7:33-54.

HALLÉ, N. 1960. Hippocratéacées nouvelles du Gabon. Notulae Systematicae 16:127-135.

HOLMGREN, P.K., HOLMGREN, N.H. \& BAINETT, L.G. 1990. Index Herbariorum. Part 1: The Herbaria of the World. 8 ed. New York Botanical Garden, New York.
MACBRIDE, J.F. 1951. Hippocrateaceae. In Flora do Peru. Publications of the Field Museum of Natural History. Botanical., ser. 13:200-220.

MENNEGA, A.M.W. 1984. Notes on new world Salacioideae (Celastraceae incl. Hippocrateaceae) I. Proceedings Koninklijke Nederlandse Akadenie Van Wetenschappen 87:81-90.

MIERS, J. 1872. On the Hippocrateaceae of South America. Transactions Linnean Society of London Botany 28:319-432.

PEYRITSCH, J. 1878. Hippocrateaceae. In Flora Brasiliensis. (C.F.P. Martius, ed) München, Wien, Leipzig, v.11, part.1, p.127-164.

PUNT, W., BLACKMORE, S., NILSSON, S. \& LE THOMAS, A. 1999. Glossary of pollen and spore terminology. http://www.biol.ruu.nl/ palaeo/glossary/glos-int.htm

RASOARIMALALA, L., ALBERS, F. \& STRAKA, H. 1982. Palynologia Madagassica et Mascarenica. Pollen et Spores 24:65-91.

RIZZINI, C.T. 1976. Salacia induta. In Contribuição ao conhecimento das floras nordestinas. Rodriguésia 28:171-172.

SALGADO-LABOURIAU, M.L. 1973. Contribuição à palinologia dos cerrados. Academia Brasileira de Ciências, Rio de Janeiro.

SMITH, A.C. 1940. The american species of Hippocrateaceae. Brittonia 3:341-571.

VIEIRA, S. 1981. Introdução à Bioestatística. Editora Campus Ltda, Rio de Janeiro. 